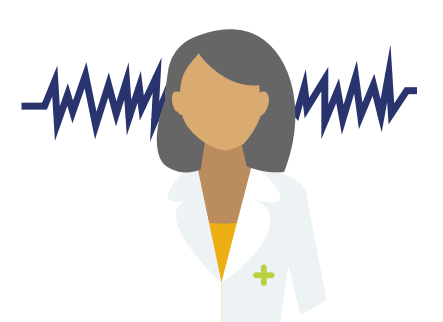

\title{
AVALIAÇÃO DO NÍVEL DE ESTRESSE OCUPACIONAL EM RESIDENTES DE UM PROGRAMA DE RESIDÊNCIA MULTIPROFISSIONAL EM SAÚDE
}

\author{
EVALUATION OF THE LEVEL OF OCCUPATIONAL STRESS IN RESIDENTS OF \\ A MULTIPROFESSIONAL RESIDENCE PROGRAM IN HEALTH
}

\begin{abstract}
Karla Cristina Kisner Balan
Terapeuta Ocupacional. Pós-graduada em Saúde Mental pela Universidade Estadual de Londrina (UEL) e em Saúde da Família pela Universidade Federal do Paraná (UFPR). E-mail: kkisnerbalan.to@gmail.com

Derivan Brito da Silva

Doutor em Sociologia pela Universidade Federal do Paraná (UFPR). E-mail: derivan_to@hotmail.com
\end{abstract} Iranise Moro Pereira Jorge

Doutora em Engenharia de Produção pela Universidade Federal de Santa Catarina (UFSC). Possui pósdoutorado em Ciências Sociais pela Universidade Nova de Lisboa. ORCID:0000-0001-9014-6801 E-mail: iranise@ufpr.br

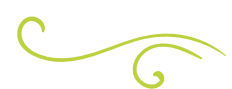

\section{RESUMO}

Trata-se de um estudo com abordagem quantitativa e exploratória descritiva de caráter transversal, que tem como objetivo avaliar o nível de estresse ocupacional e o contexto de trabalho de residentes de um programa da Universidade Federal do Paraná. Utilizou-se para a coleta de dados três questionários estruturados para traçar o perfil dos participantes e avaliar o nível de estresse através da Escala de Estresse no Trabalho (EET) e da Escala de Avaliação do Contexto de Trabalho (EACT). A análise de dados dos questionários validados foi pautada de acordo com a orientação das escalas, utilizando o Microsoft Excel como suporte para uma análise estatística descritiva. Os resultados obtidos mostram uma variação no nível de estresse entre os residentes do primeiro e segundo ano de programa. Dentre os participantes da pesquisa, cinco são do sexo masculino e vinte e três do sexo feminino, tendo-se uma média de 25,8 anos. Em relação à EACT, $57 \%$ dos residentes do primeiro ano apresentam nível crítico de estresse e 14\% nível satisfatório. Já quanto aos do segundo ano, $28 \%$ apresentam nível grave e $71 \%$ crítico. A EET mostrou que $29 \%$ dos residentes apresentam um nível satisfatório dentro da escala e $50 \%$ estão pontuados no nível crítico. Os resultados apontam um índice significativo de estresse em ambas as escalas e categorias de residentes, apontando uma necessidade de estimular a criação de métodos para minimizar o desenvolvimento de estresse no ambiente laboral, bem como a relevância da busca de estratégias para lidar com as situações vivenciadas durante o processo de especialização.

PALAVRAS-CHAVE: Saúde da Família. Estresse Ocupacional. Internato e Residência. 


\section{ABSTRACT}

This is a cross-sectional study that uses a quantitative and exploratory-descriptive approach to assess the level of occupational stress and the work context of participants in a residency program of the Federal University of Paraná. Three structured questionnaires were used to understand the profile of participants and to evaluate their level of stress according to the Occupational Stress Index (OSI) and the Work Context Assessment Index (WCAl). Data analysis of the validated questionnaires was performed in accordance with the guidelines for each index and Microsoft Excel was used for a descriptive statistical analysis. The results show a variation in the level of stress among participants in the first and second year of the program. Among participants in the study, five were males and twenty-three were females, with their average age being 25.8 years. Based on the WCAI, $57 \%$ of first-year residents were experiencing a critical level of stress and $14 \%$ were at a satisfactory level, whereas $71 \%$ of second-year residents were at a critical level and $29 \%$ at a serious level. OSI showed that $29 \%$ of residents were at a satisfactory stress level and $50 \%$ were at a critical level. The results point to a significant level of stress according to both indexes and in both categories of residents, signaling the need to promote the creation of methods to minimize stress in the work environment and to look for strategies to deal with the situations that can arise during the specialization program.

KEYWORDS: FamilyHealth. Occupational stress. Internship and Residency Programs.

\section{INTRODUÇÃO}

termo estresse foi definido pelo professor Hans Selye como "um conjunto de reações que um organismo desenvolve ao ser submetido a uma situação que exige esforço e adaptação" (FRANÇA; RODRIGUES, 2005). Segundo Glina e Rocha
(2010), todas as pessoas apresentam um nível de estresse, o qual é visto como uma resposta do organismo às exigências externas a que o corpo está exposto, necessitando em alguns casos de uma adaptação rápida, para que a pessoa consiga se manter saudável e continuar realizando suas atividades de forma adequada e conforme o esperado.

Todo estímulo externo que modifica a homeostase do ser humano é visto como um fator estressor. Autores relatam que o estresse pode ser classificado conforme suas respostas, a saber: o eustresse e o distresse. $O$ eustresse é considerado o estresse positivo, pois mesmo quando realizando esforços inesperados é possível ter um sentimento de realização e satisfação. Já o distresse, que é o estresse negativo, é caracterizado pelas respostas que não promovem a adaptação do organismo, podendo desencadear sofrimentos e até doenças. (FRANÇA; RODRIGUES, 2007; PEREIRA JORGE, 2010).

Dessa maneira, os estudos sobre estresse ganharam relevância na atualidade devido à ligação que tem sido feita entre doenças e processo de trabalho do ser humano. Quando o estresse está relacionado ao ambiente de trabalho, ele é denominado de estresse ocupacional. Segundo Lipp (2003, p. 82), o estresse ocupacional constitui-se em experiências individuais e desagradáveis que ocorrem no ambiente de trabalho, podendo ocasionar ansiedade, depressão e frustrações. Corroborando com a autora, Swan, Moraes e Cooper (1993) e Pereira Jorge (2010) relatam que o estresse relacionado ao meio laboral é resultante da incapacidade do trabalhador em lidar com os aspectos de pressão no trabalho, podendo acometer os indivíduos e a organização.

Fernandes, Medeiros e Ribeiro (2008) apontam que a necessidade de produtividade que o capitalismo impõe ao ser humano resulta em sofrimento passivo e provoca consequências físicas e mentais, dentre elas o estresse. Entre os fatores que podem desencadear o estresse estão: 
sobrecarga no trabalho e na família, carga horária excessiva de trabalho, condições inadequadas de trabalho, papéis conflituosos e ambíguos, alto grau de responsabilidade, insegurança no trabalho, autocobrança, relacionamentos interpessoais com colegas, chefia, clientes, superexposição do trabalhador, ambiente físico inadequado e pressão em relação a prazos (BALASSIANO; TAVARES; PIMENTA, 2011; KIRCHOF, 2013; PASCHOAL; TAMOYO, 2004; SADIR; BIGNOTTO; LIPP, 2010).

A residência multiprofissional em área da saúde (RMS) é um programa de pós-graduação lato sensu que favorece a inserção de profissionais de saúde no mercado de trabalho, prioritariamente no Sistema Único de Saúde (SUS). Foi criada em 2005 pelo Ministério da Educação e o Ministério da Saúde, juntamente com instituições de ensino superior, tendo como normativa a Lei 11.129 de 30 de julho (BRASIL, 2005). Possui regime de trabalho de dedicação exclusiva com carga horária de 60 horas semanais. Está dividida em períodos acadêmicos e períodos técnico/assistenciais, ficando de responsabilidade da instituição de ensino elaborar a divisão desta carga horária. Os programas de residência buscam um modelo de atenção integral e o desenvolvimento do processo de trabalho integrado entre os profissionais da saúde, constituindo um processo de educação permanente em saúde. (BRASIL, 2009).

Nesse contexto, foram criadas residências multiprofissionais em saúde da família (RMSF), que possuem como premissa a articulação dos conhecimentos dos profissionais recém-graduados com os programas ministeriais. Possuem enfoque na promoção de saúde, na integralidade do cuidado e no acolhimento, sendo capazes de favorecer o trabalho em equipe e a troca de saberes. Segundo Nascimento e Oliveira (2007), a Residência Multiprofissional em Saúde da Família é um projeto que estimula um novo olhar aos profissionais de forma humana, crítica e integral.

O Projeto Pedagógico do Programa de
Residência Multiprofissional em Saúde nesta universidade do sul do país (UFPR) tem por finalidade formar profissionais capacitados a desenvolver práticas de promoção, prevenção e recuperação da saúde. Caracteriza-se por uma experiência profissional supervisionada em parceria com dois municípios onde as atividades práticas são realizadas. Possui duração de dois anos e a cada processo de inserção no programa são abertas 18 vagas, totalizando, assim, 36 bolsas/ano que são subdivididas em seis categorias profissionais: enfermagem, farmácia, medicina veterinária, nutrição, odontologia e terapia ocupacional. Ressalta-se que as vagas não são distribuídas de forma igualitária, sendo que as profissões inseridas recentemente no programa (medicina veterinária e terapia ocupacional) possuem duas vagas, enquanto as demais profissões possuem quatro vagas. (UFPR, 2016).

Existem vários estudos sobre estresse ocupacional ou burnout em programas de residência médica e multiprofissional (CAHÚ et al., 2014; FREITAS; SILVA JUNIOR; MACHADO, 2016; LIMA et al., 2007; LORENÇÃO; MOSCARDINI; SOLER, 2010; SANCHES et al., 2016; SILVA; SILVEIRA, 2017). Este fato mostra a relevância de se estudar tal tema correlacionado ao público em questão, visto que serão estes profissionais que posteriormente estarão inseridos no mercado formal de trabalho.

Assim, este trabalho tem como objetivo avaliar o nível de estresse ocupacional e o contexto de trabalho dos residentes do Programa de Residência Multiprofissional em Saúde da Família (PRMSF), da Universidade Federal do Paraná.

\section{METODOLOGIA}

Trata-se de um estudo com abordagem quantitativa, exploratória descritiva de caráter transversal, aprovado pelo Comitê de Ética em Pesquisa em Seres Humanos do Setor de Ciências da Saúde da Universidade Federal do Paraná em 30 de outubro de 
2017 sob parecer $n^{\circ}$ 2356176. A pesquisa foi realizada no período de outubro de 2017 a dezembro de 2017. Para garantir o anonimato e o sigilo dos participantes e dos municípios, estes dados serão mostrados de forma sigilosa utilizando-se uma nomenclatura com letras e números, cumprindo com a resolução 466/12 CNS.

A pesquisa foi realizada com residentes que ingressaram no PRMSF em 2016 e 2017, tendo como critério de inclusão residentes ativos do programa, de ambos os sexos. Quanto às nomenclaturas, será utilizado R1 para se referir ao conjunto de residentes que ingressaram em 2017 e R2 para os que ingressaram em 2016, seguido de um número (1 a 28). No caso dos municípios onde são desenvolvidas majoritariamente as atividades técnico-assistenciais, estes serão identificados pelos números 1 e 2 .

Das 36 vagas disponíveis no programa de residência, no momento da pesquisa existiam 33 residentes ativos. Este número deve-se à desistência de três profissionais, sendo uma farmacêutica (R1), uma enfermeira e uma cirurgiã-dentista (R2). Dos 33 residentes que se encaixam no critério de inclusão para a pesquisa, participaram 28, dos quais 14 são R1 e 14 R2. Dois residentes não aceitaram participar, outros dois não foram encontrados para entrega dos questionários. Ressalta-se também que a pesquisadora-residente não respondeu aos questionários

Para a coleta de dados foram distribuídos três questionários estruturados. $O$ primeiro foi elaborado pelas pesquisadoras com o intuito de realizar um levantamento do perfil sociodemográfico dos participantes da pesquisa. Neste questionário, foram buscadas informações relativas a: idade, estado civil e tempo de residência. Os outros dois questionários são validados, com questões objetivas que avaliam o nível de estresse dos participantes. São eles: (1) Escala de Estresse no Trabalho (EET), que aborda estressores variados e reações emocionais; (2) Escala de Avaliação do Contexto de Trabalho (EACT), que permite diagnosticar a organização, as condições e as relações socioprofissionais de trabalho.

A EET, validada por Paschoal e Tamayo (2004), aborda itens relacionados a estressores organizacionais e suas reações psicológicas. Trata-se de um questionário composto por 23 questões autoaplicáveis, utilizando uma escala de concordância de cinco pontos do tipo: (1) discordo totalmente, (2) discordo, (3) concordo em partes, (4) concordo e (5) concordo totalmente. A maior pontuação é atribuída ao maior nível de estresse.

Por sua vez, a EACT é composta por 31 itens distribuídos em três dimensões: condições de trabalho (10 questões), organização do trabalho (11 questões) e relações socioprofissionais de trabalho (10 questões). É composta por uma escala do tipo Likert, constituída com base em itens negativos em que o participante deve responder às questões com as afirmações: (1) nunca, (2) raramente, (3) às vezes, (4) frequentemente e (5) sempre. O objetivo da escala é analisar a percepção que o trabalhador tem de seu trabalho atual. (MENDES; FERREIRA, 2008).

A análise e a sistematização dos dados foram realizadas primeiramente com auxílio do software Microsoft Excel para descrever o perfil dos participantes. Logo em seguida, construiu-se a análise estatística descritiva (quantitativa) das respostas dos dois questionários (EET e EACT), a qual seguiu as orientações dos autores em relação aos dados.

\section{RESULTADOS}

Inicialmente apresentam-se os dados obtidos a partir do questionário sociodemográfico, a partir do qual foi possível traçar um perfil dos participantes, como sexo, idade, estado civil, área de formação, tempo de programa e cidade onde realiza as atividades (tabela 1).

A média de idade dos participantes foi de 25,8 anos, já no que se refere ao sexo, cinco participantes eram do sexo masculino e vinte e três do sexo feminino. Com relação ao estado civil dos participantes, $82 \%$ 
são solteiros e 4\% possuem união estável. Observou-se que $21,42 \%$ dos participantes moram sozinhos.

As áreas de formação profissional dos participantes estão distribuídas da seguinte forma: Enfermagem (2), Farmácia (7), Medicina Veterinária (3), Nutrição (7), Odontologia (6) e Terapia Ocupacional (3). Quatorze participantes estão fazendo o primeiro ano no programa (R1) e quatorze estão no segundo (R2). Em relação ao campo de prática, treze participantes realizam as atividades técnico-assistenciais no município 1 e quinze no município 2, sendo que os participantes médicos-veterinários também realizam algumas atividades no município de Curitiba em ambos os anos.

Em relação ao deslocamento para acesso aos campos de prática (serviços de saúde) e às instituições de ensino (atividades acadêmicas), 43\% dos participantes utilizam transporte coletivo e $14 \%$ usam carona com outros participantes. O tempo médio é de meia hora a uma hora de deslocamento.

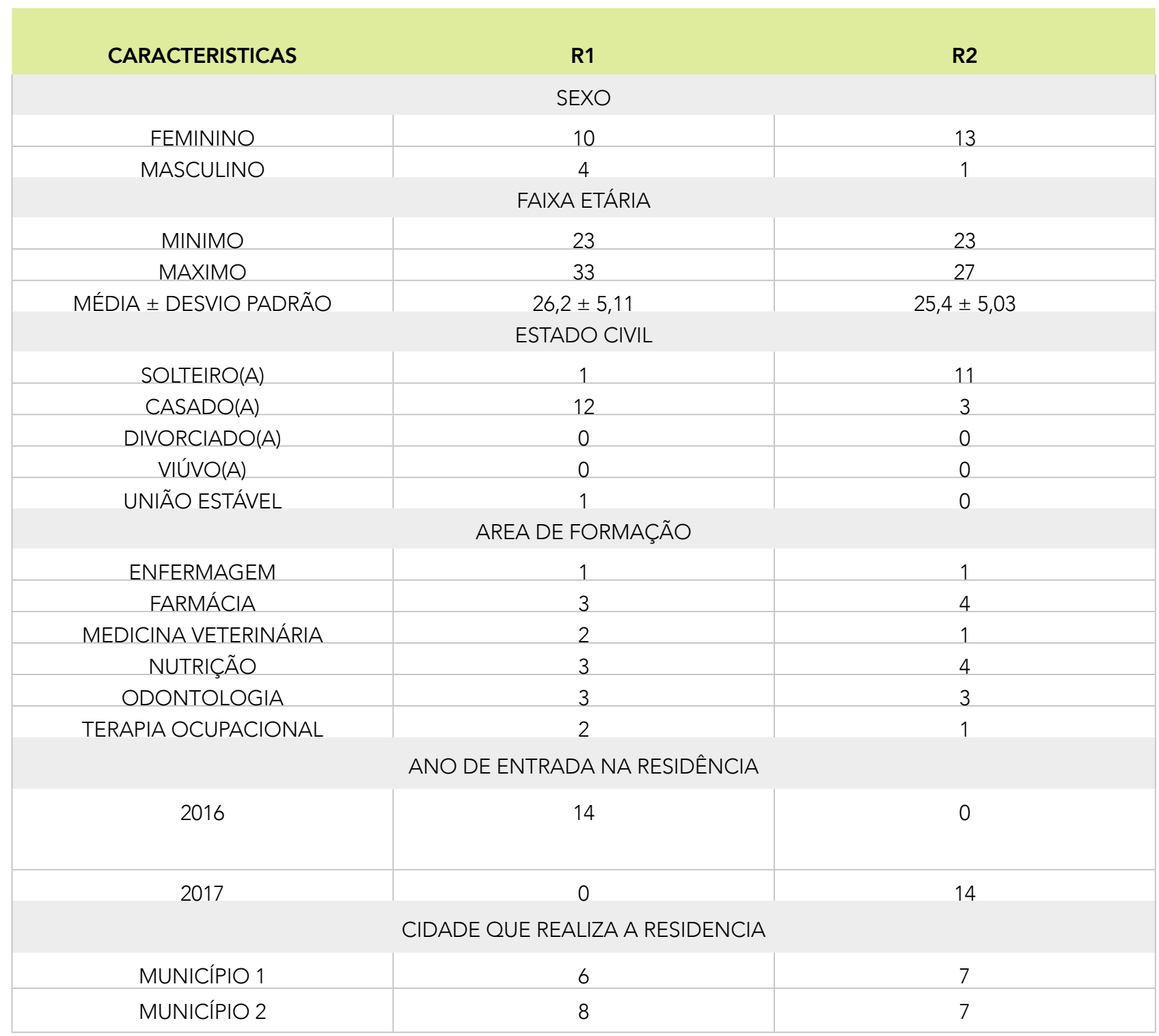

Tabela 1 - Características sociodemográficas de residentes do Programa de Residência Multiprofissional em Saúde da Família da UFPR. 
Sobre o tempo utilizado para programar as atividades previstas no programa, os participantes foram questionados separadamente quanto a: planejamento de atividades coletivas, atendimentos individuais e atividades acadêmicas. Dessa forma, em relação às atividades práticas, os participantes deveriam responder: "Dentro das 40 horas semanais destinadas às atividades práticas, quantas horas você utiliza para planejar as atividades coletivas/atividades individuais?". Em relação às atividades acadêmicas a pergunta a ser respondida era "Dentro das 20 horas semanais destinadas às atividades acadêmicas, quantas horas você utiliza para elaboração de trabalhos acadêmicos?". As respostas estão apresentadas na Tabela 2 e mostram que não existe uma diferença notável entre os grupos de residentes (R1 e R2), sendo que a grande maioria utiliza menos de $10 \%$ da carga horária para planejar suas atividades.

\begin{tabular}{|c|c|c|}
\hline \begin{tabular}{|l|} 
PANEJAMENTO DAS \\
ATIVIDADES
\end{tabular} & R2 \\
\hline \multicolumn{2}{|c|}{ ATIVIDADES COLETIVAS } & \\
\hline MENOS DE 4 HORAS & 9 & 9 \\
\hline DE 4 a 8 HORAS & 3 & 4 \\
\hline MAIS DE 8 HORAS & 2 & 1 \\
\hline ATIVIDADES INDIVIDUAIS & \\
\hline MENOS DE 4 HORAS & 6 & 5 \\
\hline DE 4 a 8 HORAS & 4 & 7 \\
\hline MAIS DE 8 HORAS & 4 & 2 \\
\hline ATIVIDADES ACADEMICAS & \\
\hline MENOS DE 2 HORAS & 4 & 1 \\
\hline DE 2 HORAS a 4HORAS & 8 & 8 \\
\hline MAIS DE 4 HORAS & 2 & 5 \\
\hline
\end{tabular}

Tabela 2 - Tempo dedicado para planejamento de atividades previstas no programa de acordo com a carga horária total de 60 horas

Fonte: autoria própria (2017).

Em relação aos afastamentos previstos em lei (afastamento médico, casamento, gravidez e óbito), dentre os participantes $28,57 \%$ se afastaram por causas médicas, sendo que nenhum afastamento durou mais de 15 dias; 7,14\% tiveram afastamento devido a casamento; e 7,14\% devido a óbito de um familiar de primeiro grau.

Frente ao questionamento "Você se sente estressado?", 96,42\% dos participantes responderam que possuem uma percepção de sentimento de estresse e indicaram como fatores que levam a tal sentimento: elevada carga horária do programa, excesso de atividades, falta de reconhecimento e relacionamento interpessoal com as equipes de saúde.

Posteriormente, questionou-se sobre a realização de atividades para lidar com o estresse. Do grupo R1, 50\% realizam pelo menos uma atividade e $35,71 \%$ realizam mais de uma. Já no grupo R2, 50\% realizam pelo menos uma, $21,42 \%$ mais de uma atividade e 7,14\% dos residentes precisou parar de realizar uma atividade devido à carga horária e atividades previstas pelo programa de residência. Na tabela 3, é possível verificar as atividades que compunham o questionário e seus respectivos resultados.

\begin{tabular}{|c|c|c|}
\hline \multicolumn{1}{|c|}{ ATIVIDADES } & R1 & R2 \\
\hline ESPORTE & 7 & 2 \\
\hline ARTES & 3 & 4 \\
\hline PRATICAS INTEGRATIVAS & 7 & 4 \\
\hline COMPLEMENTARES & & \\
\hline TERAPIA & 3 & 3 \\
\hline
\end{tabular}

Tabela 3 - Atividades realizadas para lidar com o estresse Fonte: autoria própria (2017).

Serão apresentados a seguir os resultados da EET, os quais relacionam um estressor à reação que ele causa no trabalhador. Foram realizadas três análises distintas com este questionário, separando, em cada análise, os participantes de acordo com o tempo de programa. A primeira análise foi realizada por participante, a segunda de acordo com os itens do questionário e a terceira por município.

Ao analisar as médias de cada participante do R1, foi possível constatar uma variação nos níveis de estresse, na qual, de um total de quatorze participantes, $28,57 \%$ se encontram em um nível satisfatório, 57,14\% em 
nível crítico e 14,28\% grave, sendo a menor média 1,04 e a maior 4,39. Já dos quatorze participantes do R2, 28,57\% estão, na escala, em nível satisfatório, $42,85 \%$ crítico e $28,57 \%$ já atingem o nível grave de estresse, sendo a menor média 1,61 e a maior 4,65 .

Ao calcular a média de cada questão, é possível verificar os estressores mais presentes no ambiente de acordo com a percepção dos participantes. Os três estressores com maior média para os R1 são: "o ritmo de trabalho acelerado $(3,36)$ ", "o mobiliário existente no local de trabalho é inadequado $(3,86)$ " e "a distribuição das tarefas é injusta $(3,50)^{\prime \prime}$. Em relação aos R2, trata-se de que "as condições de trabalho são precárias $(3,69) "$, "existe barulho no ambiente de trabalho $(3,43)$ " e "os equipamentos necessários para realização das tarefas são precários $(4,36)$ ".

A figura 1 mostra as médias da EET em relação aos municípios. Nos dois municípios, os residentes de ambos os anos apresentam média acima de 2,3. Dessa maneira, percebe-se que os residentes em sua maioria apresentam um nível crítico de estresse. É possível verificar ainda uma média maior nos residentes lotados no município 2, sendo que no mesmo município existe uma diferença significativa entre R1 e R2.

\section{Escala de Estresse no Trabalho}

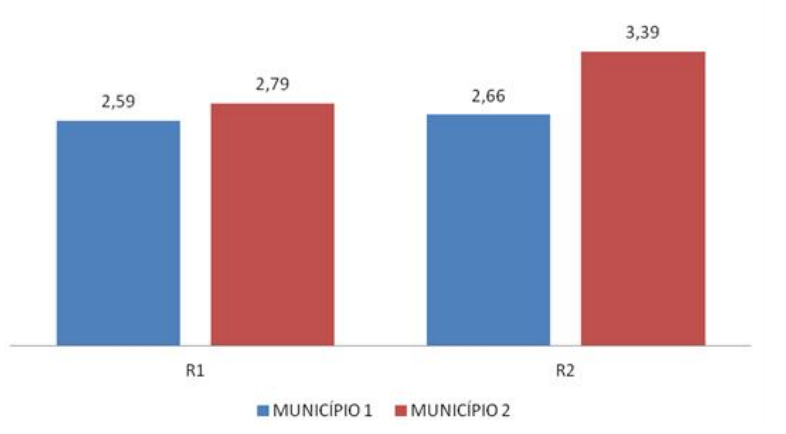

Figura 1 - Média referente a Escala de Estresse no Trabalho por município.

Fonte: autoria própria (2017).

Para a análise da EACT (a qual avalia aspectos relacionados à organização do trabalho, condições de trabalho e relações socioprofissionais), foram consideradas as subdivisões de seus fatores, relacionando-os com: os participantes, os dois grupos e os municípios. Os dados serão descritos a seguir.

A tabela 4 descreve a média de cada participante subdividida pelos fatores que compõem a escala. Dos vinte e oito participantes, apenas 1 (R1-11) apresenta um estresse satisfatório nos três fatores da escala, ao passo que $14,28 \%$ apresentam estresse grave (R1-10; R2-5; R2-7; R2-11) e 82,14\% estão no nível crítico. Vale ressaltar que o R1-11 e o R2-11 são da mesma categoria profissional e apresentam níveis de estresse significantemente diferentes nos três fatores.

$\begin{array}{ccc}\text { Condições } & \text { Organização } & \text { Relações } \\ \text { de Trabalho } & \text { de Trabalho } & \text { Socioprofissionais }\end{array}$

\begin{tabular}{|c|c|c|c|}
\hline R1-1 & 4,1 & 4,7 & 3 \\
\hline R1-2 & 3,3 & 3,3 & 2 \\
\hline R1-3 & 3,2 & 2,9 & 3,2 \\
\hline R1-4 & 2,7 & 3,9 & 3,8 \\
\hline R1-5 & 2,1 & 4,5 & 2,3 \\
\hline R1-6 & 4,2 & 2,9 & 3,5 \\
\hline R1-7 & 2,7 & 3,5 & 4,2 \\
\hline R1-8 & 3,4 & 3,2 & 3,2 \\
\hline R1-9 & 3,1 & 3,9 & 4,6 \\
\hline R1-10 & 4,3 & 4 & 4,3 \\
\hline R1-11 & 1,4 & 2,3 & 1,6 \\
\hline R1-12 & 3,6 & 3,9 & 3,3 \\
\hline R1-13 & 3,6 & 3,7 & 3,4 \\
\hline R1-14 & 3,5 & 1,8 & 2,4 \\
\hline R2-1 & 4,3 & 3,7 & 3,6 \\
\hline R2-2 & 3 & 2,5 & 2,2 \\
\hline R2-3 & 2,6 & 3,4 & 3,6 \\
\hline R2-4 & 2,7 & 2,8 & 4,1 \\
\hline R2-5 & 4,1 & 3,7 & 4,1 \\
\hline R2-6 & 3,5 & 2,5 & 3,5 \\
\hline R2-7 & 4,1 & 4,1 & 3,9 \\
\hline R2-8 & 3,6 & 3,5 & 3,1 \\
\hline R2-9 & 4 & 3,1 & 2,7 \\
\hline R2-10 & 4,1 & 4,3 & 1,7 \\
\hline R2-11 & 4,4 & 4,2 & 4,5 \\
\hline R2-12 & 3,2 & 4,3 & 2,1 \\
\hline R2-13 & 3,5 & 3,1 & 2,5 \\
\hline R2-14 & 3,3 & 3,5 & 4,90 \\
\hline
\end{tabular}

Tabela 4 - Média dos fatores da EACT por participantes 
A figura 2 mostra os resultados obtidos da EACT por tempo de programa de residência. É possível analisar que, em relação à organização do trabalho, existe uma diferença de 0,02 entre os dois grupos. Já em relação às condições de trabalho, verifica-se que os participantes que estão no segundo ano do programa (R2) apresentam um estresse que margeia o nível grave na escala, pontuando uma média de 3,63.

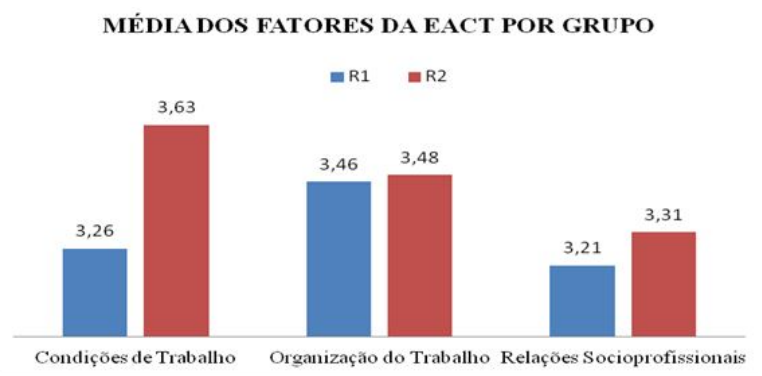

Figura 2 - Média dos fatores da EACT por tempo de programa de residência

Fonte: autoria própria (2017).

Quando comparados os dados de acordo com o tempo de programa e o município de atuação (figura 3) é possível perceber que os residentes lotados no município 1 e que estão em seu primeiro ano de programa apresentam média maior no fator organização do trabalho $(3,62)$. Já os participantes que estão em seu segundo ano de programa possuem média maior no fator de condições de trabalho $(4,46)$. Ao analisar os dados do município 2, é possível perceber que ambos os grupos de residentes possuem média mais elevada no fator condições de trabalho, sendo R1 com 3,39 e R2 com 4.09

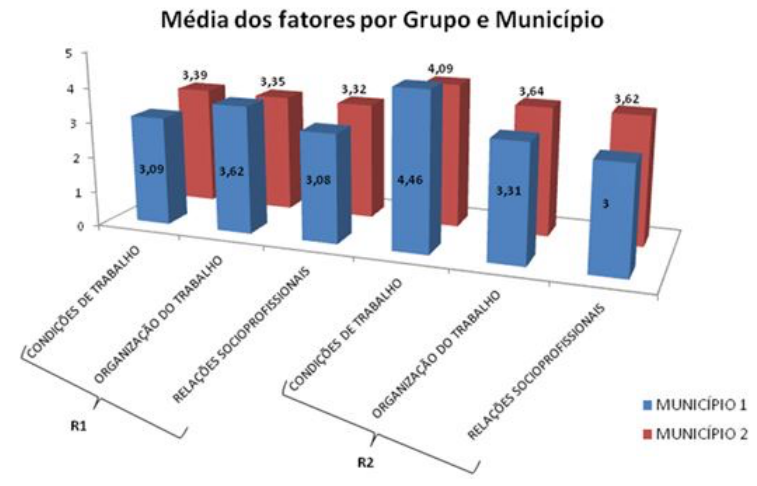

Figura 3 - Média dos fatores da EACT por tempo de programa e município.

Fonte: autoria própria (2017).

\section{DISCUSSÃO}

O estresse ocupacional é um termo que tem sido discutido há alguns anos. No ano de 2017, o Tribunal Superior do Trabalho elegeu os transtornos mentais relacionados ao trabalho como tema para discussão do Programa Trabalho Seguro, devido ao aumento significativo desse fator como motivo de afastamentos no INSS, ocupando o terceiro lugar na lista de pagamento de benefício (TST, 2016).

○ questionário sociodemográfico traça um perfil dos participantes, possibilitando uma percepção de situações que interferem no papel ocupacional em que os residentes se encontram. Estudos apontam que a dupla jornada influencia não apenas o papel do trabalhador, mas também as relações interpessoais (HALBESLEBEN; ZELLARS, 2007). Os participantes da pesquisa possuem uma média de idade de 25,8 anos, dos quais $14,28 \%$ possuem mestrado e $64,28 \%$ concluíram a graduação no ano anterior ao ingresso da residência. Silva e Silveira (2017) apontam em seu estudo que os participantes mais novos estão mais propensos ao não enfrentamento de situações de estresse, pois os jovens mostram-se menos dispostos a superar os desgastes recorrentes no contexto profissional e pessoal (esta situação também é verificada na atual pesquisa). Apesar dos residentes disporem de momentos com seus tutores para esclarecimentos e discussões de casos, isto não minimiza a insegurança e a percepção de estresse. Nesse sentido, Sanches et al. (2016) pontuam a inexperiência profissional, o medo de cometer erros, a cobrança e as responsabilidades impostas como fatores que podem explicar o adoecimento do público em questão, visto que o programa de residência prioriza o treinamento de recém-graduados.

Em relação ao questionário sociodemográfico, dois itens ainda se destacam. São eles: o gênero feminino e o tempo de deslocamento até o campo de prática. Dessa 
forma, Rezende (2012) relata que os tipos de meios de transporte e o tempo de duração do deslocamento oferecem estímulos estressantes, influenciando no desencadeamento de situações de estresse que, de forma negativa e repetitiva, podem levar os indivíduos a doenças.

Ademais, foi possível observar na pesquisa que $82 \%$ dos participantes é do sexo feminino. Araújo et al (2006) apontam que no campo do trabalho existe um perfil socialmente construído ao longo do tempo, no qual as mulheres exercem papéis e abordagens profissionais aprendidas e desenvolvidas com alguma similaridade com o âmbito doméstico, envolvendo o cuidar e o educar. Corroborando com os dados obtidos, estudos mostram que em cursos de graduação da área de saúde a prevalência de mulheres é significativamente maior (DONATI; ALVES; CAMELO, 2010; NARDELLI et al. 2013).

Observou-se que quando perguntados sobre a percepção de estresse, dos vinte e oito participantes da pesquisa, 96,42\% responderam que se sentem estressados e indicaram como alguns fatores estressantes: a carga-horária elevada, a falta de tempo para realizar planejamentos de atividades, as relações interpessoais entre todos os profissionais, o trabalho dentro de unidade básica de saúde, a falta de clareza nas atribuições aos residentes, a falta de reconhecimento da categoria residente, a demanda elevada de atividades, o tempo perdido em deslocamento até o local de trabalho e a dificuldade em correlacionar conteúdos teóricos da residência com o campo de prática.

Contribuindo com isto, Sanches et al. (2016) salientam em seus estudos que a carga-horária elevada dos programas de residência multiprofissional, estipulada pelo Ministério da Saúde e pelo Ministério da Educação, é um outro fator que pode se relacionar o desgaste físico e emocional dos ingressos no programa. Os residentes devem cumprir as normativas que estipulam $80 \%$ de atividades práticas e $20 \%$ de atividades teóricas (BRASIL, 2010). O PRMSF desta pesquisa possui um vínculo com Serviços de Atenção Básica à Saúde na lógica da Estratégia de Saúde da Família, realizando uma carga-horária de 40 horas semanais e atividades esporádicas aos sábados, como campanhas de vacinação, feiras de saúde e programas de prevenção, como a coleta do exame preventivo ao câncer de útero. As demais horas são divididas em atividades teóricas, tendo aulas com disciplinas comuns a todas as áreas de atuação, disciplinas específicas por eixo e tutoriais de campo e área, completando as 60 horas semanais previstas por lei. Entretanto, quando comparado a outros PRMS, observa-se que, devido à lógica da Estratégia de Saúde da Família, por vezes a carga-horária total não é efetivamente cumprida na proporção $80 \%$ a $20 \%$.

Nota-se que a EET demonstra que $71 \%$ dos residentes R1 encontram-se em situações de estresse e que $71 \%$ dos R2 estão na mesma condição de estresse. Foi possível constatar que os residentes R2 do programa apresentam médias maiores, quando referem-se aos locais de trabalho pontuados como inadequados ou precários, causando, assim, uma insatisfação laboral, fator este que pode ocasionar estresse ocupacional. Os resultados apontados nesta pesquisa, sobre a existência de $71 \%$ de estresse entre os residentes, não são compatíveis com os apresentados por Guido et al (2012), em que constatou-se que $51,35 \%$ dos residentes em saúde da família/atenção básica apresentam baixo estresse.

Cabe ressaltar que altos níveis de estresse acarretam dificuldades em cinco áreas da vida: social, afetiva, profissional, espiritual e da saúde (MALAGRIS; FIORITO, 2006). Dessa forma, cada profissional deve ter a consciência da necessidade de elaboração de um programa de estratégias que diminuam esse estresse, de acordo com sua rotina diária e seus hábitos de vida. Pesquisas recentes mostram que estratégias de coping são importantes para lidar com 
situações adversas, não apenas no meio organizacional, e que tais estratégias podem ser determinantes para saúde física, mental e social do ser humano (GUIDO et al., 2012).

Percebe-se que os integrantes do R1 conseguem organizar sua rotina diária, possibilitando realizar mais de uma atividade que estimule uma melhor qualidade de vida, como, por exemplo, esportes, artesanato, práticas integrativas complementares e algum tipo de terapia. Ao contrário dos residentes $\mathrm{R} 2$, que, ao serem questionados se realizam alguma atividade, pontuaram apenas uma ou nenhuma atividade.

Assim como a EET, a escala EACT confirma que $82,14 \%$ dos residentes R1 e R2 estão no nível crítico de estresse. Dentre todas as análises, notou-se que os pertencentes ao R2 apresentam índices e classificação de estresse maiores, sendo que uma residente (R2-11), em uma escala de 0 a 5, apresenta nível elevado, com média de 4,4/4,2/4,5. 0 município 2 destaca-se dentre os índices de maior estresse.

Ressalta-se que, neste contexto, não é possível afirmar o porquê desta diferença entre os R1 e R2, porém existe uma hipótese que pode ser levantada: no segundo ano, além de toda a sobrecarga referente ao processo de residência, os residentes iniciam o Trabalho de Conclusão da Residência (TCR), que envolve a pesquisa bibliográfica, a coleta de dados e, posteriormente, a escrita do artigo, atividade esta que desprende tempo e maior dedicação dos residentes. Outra explicação é apontada por Cahú et al. (2014), que relatam em seus estudos que os níveis de estresse variam entre residentes que estão iniciando o programa (R1) e os que estão em seu segundo ano de residência (R2), tendo a qualidade de vida afetada de forma significativa.

Referente aos itens avaliados pela EACT, observa-se que para os R1 a organização de trabalho é a que foi mais pontuada, isto relacionado ao município 1. Já para os R2, em ambos os municípios destacam-se negativamente as condições de trabalho.
A organização de trabalho tem um forte impacto na integridade biopsicossocial dos trabalhadores, tanto pelas questões organizacionais como pelos aspectos produtivos e tecnológicos, causando em alguns momentos uma tensão no cotidiano laboral, que podem ser percebidas por sinais e sintomas de estresse. (GREENBERG, 2002; LIPP, 2003; JEX, 2007; PEREIRA JORGE, 2010).

As condições de trabalho inadequadas podem contribuir com o aparecimento de doenças físicas ou mentais, de forma que Glina et al. (2001) apontam que tais condições não interferem sozinhas na qualidade de vida do trabalhador. Elas podem ocorrer de forma concomitante aos outros problemas do ambiente laboral, como a organização de trabalho.

Os profissionais de saúde se desgastam não só pela alta demanda de carga de trabalho, como também pelas tarefas árduas que têm que desempenhar. Estudos apontam que estes profissionais estão mais propensos a apresentarem estresse relacionado ao trabalho, pelo fato de lidar com doenças de outros, contexto no qual estão inseridos os residentes que apresentam uma variação extra, as atividades acadêmicas. (CARVALHO, MALAGRIS, 2007)

\section{CONCLUSÃO}

O programa de RMSF compreende uma proposta de treinamento em serviço de recém-graduados, buscando uma melhor capacitação de tais profissionais para posteriormente serem inseridos no mercado formal. Os resultados da pesquisam mostram índices significativos de estresse entre os residentes de ambos os anos do programa.

Segundo Rocha (2016), a prevenção primária neste tipo de estresse é essencial para lidar com a situação e não chegar aos níveis mais elevados, como o burnout, que é caracterizado como um estresse crônico, causado por um desgaste emocional e físico (NABERGOI, BOTINELLI, 2004). Este 
tipo de prevenção tem como características eliminar, reduzir ou alterar os estressores, modificando elementos nos quais são organizados os processos de trabalho.

Destaca-se, assim, a importância de criar estratégias para que seja possível minimizar níveis de estresse tanto em nível organizacional quanto pessoal, visto que o estresse não acontece apenas no ambiente laboral, mas está associado a diversos fatores da vida das pessoas. 


\section{REFERÊNCIAS}

ARAÚJO, T. M. de et al. Diferenciais de gênero no trabalho docente e repercussões sobre a saúde. Ciência \& Saúde Coletiva, v. 11, n. 4, p. 1117-1129, 2006. Disponível em: <https://www.scielosp.org/pdf/ csc/2006.v11n4/1117-1129/pt>. Acesso em: 20 fev. 2018.

BALASSIANO, M.; TAVARES, E.; PIMENTA, R. da. C. Estresse Ocupacional na administração pública brasileira: quais os fatores impactantes? Revista de Administração Pública, Rio de Janeiro, v. 45, n. 3, p. 751-774, maio/jun. 2011. Disponível em: <http://www.redalyc. org/html/2410/241019893009/>. Acesso em: 30 jan. 2018.

BRASIL. Decreto-lei n 11.129 de 30 de junho de 2005. Institui o Programa Nacional de Inclusão de Jovens - ProJovem; Cria - Conselho Nacional da Juventude e a Secretaria Nacional de Juventude; altera as leis n 10.683, de 28 de maio de 2003 e 10.429 de 24 de abril de 2002; e da outras providências. Diário Oficial [da] República Federativa do Brasil, Brasília, DF, 30 jun. 2005. Disponível em: <http://www.planalto.gov.br/ccivil_03/_ato2004-2006/2005/lei/ |11129.htm>. Acesso em: 21 out. 2016.

BRASIL. Portaria Interministerial MEC/MS n 1.077, de 12 de novembro de 2009. Dispõe sobre a Residência Multiprofissional em Saúde e a Residência em Área Profissional da Saúde, e institui o Programa Nacional de Bolsas para Residências Multiprofissionais e em Área Profissional da Saúde e a Comissão Nacional de Residência Multiprofissional em Saúde. Diário Oficial [da] República Federativa do Brasil, Brasília, DF, 13 nov. 2009. Disponível em: <http://www. cremesp.org.br/library/modulos/legislacao/versao_impressao. php?id=8862>. Acesso em: 21 out. 2016.

BRASIL. Resolução n 3 de 4 de maio de 2010. Dispõe sobre a duração e a carga horária dos programas de Residência Multiprofissional em Saúde e de Residência em área Profissional da Saúde e sobre a avaliação e a freqüência dos profissionais da saúde residentes. Diário Oficial [da] República Federativa do Brasil, Brasília, DF, 5 maio 2010. Disponível em: <http://portal.mec.gov.br/index. php?option=com_docman\&view=download\&alias=15449-resolcnrms-n3-04maio-2010\&Itemid=30192>. Acesso em: 5 out. 2016.

CAHÚ, R. A. G. et al. Estresse e qualidade de vida em residência multiprofissional em saúde. Revista Brasileira de Terapias Cognitivas, Rio de Janeiro, v. 10, n. 2, p. 16-83, dez. 2014. Disponível em: <http:// pepsic.bvsalud.org/pdf/rbtc/v10n2/v10n2a03.pdf>. Acesso em: 9 nov. 2016. 
CARVALHO, L. de; MALAGRIS, L. E. N. Avaliação do nível de stress em profissionais de saúde. Estudos e pesquisas em psicologia, Rio de Janeiro, v. 7, n. 3, p. 570-582, dez. 2007. Disponível em: <http://www.e-publicacoes_teste.uerj.br/index.php/revispsi/article/ view/10881/8563>. Acesso em: 31 jan. 2018.

DONATI, L.; ALVES, M. J; CAMELO, S. H. H. O perfil do estudante ingressante no curso de graduação em enfermagem de uma faculdade privada. Revista de enfermagem, Rio de Janeiro, v. 18, n. 3, p. 446-450, jul./set. 2010. Disponível em: <http://www.facenf.uerj.br/ v18n3/v18n3a19.pdf>. Acesso em: 20 fev. 2018.

FERNANDES, S. M. B. A.; MEDEIROS, S. M.; RIBEIRO, L. M. Estresse Ocupacional e o mundo do trabalho atual: repercussões na vida cotidiana das enfermeiras. Revista Eletrônica de Enfermagem, v. 10, n. 2, p. 414-427, 2008. Disponível em: <https://www.fen.ufg.br/revista/ v10/n2/pdf/v10n2a13.pdf>. Acesso em: 20 fev. 2018.

FRANÇA, A. C. L.; RODRIGUES, A. L. Stress e trabalho: uma abordagem psicossomática. 4. ed. São Paulo: Atlas, 2005.

FRANÇA, A. C.; RODRIGUES, A. L. Estresse e Trabalho: Guia básico com abordagem psicossomática. São Paulo: Atlas, 2007.

FREITAS, M. de A. de; SILVA JUNIOR, O. C. da.; MACHADO, D. A. Nível de estresse e qualidade de vida de enfermeiros residentes. Revista de Enfermagem UFPE on line, Recife, v. 10, n. 2, p. 623630, fev. 2016. Disponível em: <https://periodicos.ufpe.br/revistas/ revistaenfermagem/article/view/10998/12357>. Acesso em: 30 jan. 2018.

GLINA, D. M. R. et al. Saúde Mental e trabalho: uma reflexão sobre o nexo com o trabalho e o diagnóstico, com base na prática. Caderno de Saúde Pública, Rio de Janeiro, v. 17, n. 3, p. 601-616, maio/ jun. 2001. Disponível em: <https://www.scielosp.org/pdf/csp/2001. v17n3/607-616/pt>. Acesso em: 31 jan. 2018.

GLINA, D. M. R.; ROCHA, L. E. Saúde Mental no trabalho: da teoria à prática. São Paulo: Roca, 2010.

GREENBERG, J. S. Administração do estresse. São Paulo: Manole, 2002.

GUIDO, L. de A. et al. Estresse e Burnout entre residentes multiprofissionais. Revista Latino-Americana de Enfermagem, v. 20, n. 6, nov./dez. 2012. Disponível em: <http://www.scielo.br/pdf/rlae/ v20n6/pt_08.pdf>. Acesso em: 4 jan. 2018. 
HALBESLEBEN, J. R. B.; ZELLARS, K. L. Stress e a interface trabalho família. In: ROSSI, A. M.; PERREUÉ, P. L.; SAUTER, S. L. (Org.). Stress e Qualidade de Vida no Trabalho: perspectivas atuais da saúde ocupacional. 1. ed. São Paulo: ATLAS, 2007. p. 56.

JEX, S. M. et al. Stress e eficácia dos funcionários. In: ROSSI, A. M.; PERREWÉ, P. L.; SAUTER, S. L. Stress e qualidade de vida no trabalho: perspectivas atuais da saúde ocupacional. São Paulo: Atlas, 2007.

KIRCHHOF, R. S. Esrtresse, Coping, Sindrome de Bournout, Sintomas Depressivos e Hardness em Docentes de Enfermagem. 2013. $150 f$. Dissertação (Mestrado em Enfermagem) - Universidade Federal de Santa Maria, Santa Maria, 2013.

LIMA, F. D et al. Síndrome de Burnout em Residentes da Universidade Federal de Uberlandia -2004. Revista Brasileira de Educação Médica, v. 31, n. 2, p. 137-146, 2007. Disponível em: <http://www.scielo.br/pdf/\%0D/rbem/v31n2/03.pdf>. Acesso em: 30 jan. 2018.

LIPP, M. E. N. (Org.). Mecanismos neuropsicofisiológicos do stress: teoria e aplicação clínica. São Paulo: Casa do Psicólogo, 2003.

LOURENÇÃO, L. G.; MOSCARDINI, A. C.; SOLER, Z. A. S. G. Saúde e Qualidade de Vida em médicos residentes. Rev Assoc Med Bras., São Paulo, v. 56, n. 1, p. 81-91, 2010. Disponível em: <http://formsus. datasus.gov.br/novoimgarq/7043/827173_90655.pdf>. Acesso em: 30 jan. 2018.

MALAGRIS, L. E. N; FIORITO, A. C. C. Avaliação do nível de stress de técnicos da área de saúde. Estudos de Psicologia/Campinas, v. 23, n. 4, p. 391-398, out/dez. 2006. Disponível em: <http://www.scielo.br/ pdf/estpsi/v23n4/v23n4a07.pdf>. Acesso em: 5 out. 2017.

MENDES, A. M.; FERREIRA, M. C. Contexto de Trabalho. In: SIQUEIRA, M. M. M. (Org.). Medidas de comportamento organizacional: Ferramentas e Diagnóstico e Gestão. Porto Alegre, RS, 2008. Disponível em: <http://www.ergopublic.com.br/ arquivos/1256235723.18-arquivo.pdf>. Acesso em: 5 out. 2017.

NABERGOI, M.; BOTTINELLI, M. M. Saúde do terapeuta ocupacional como trabalhador. Síndrome de Burnout: eixo para pensar nas relações entre reflexividade, pesquisa e prática. In: LACMAN, S. (Org.). Saúde, trabalho e terapia ocupacional. São Paulo: Roca, 2004. cap. 10. p. 187-207. 
NARDELLI, G. G. et al. Perfil dos alunos ingressantes dos cursos da área da saúde de uma universidade federal. Revista de Enfermagem e Atenção à Saúde, Minas Gerais, v. 2, n. 1, p. 3-12, 2013. Disponível em: <http://seer.uftm.edu.br/revistaeletronica/index.php/enfer/ article/view/405/383 >. Acesso em: 20 fev. 2018.

NASCIMENTO, D. D. G. do; OLIVEIRA, M. A. de C. Competências profissionais e o processo de formação na residência multiprofissional em Saúde da Família. Saúde e Sociedade, v. 19, n. 14, p. 814-827, 2010. Disponível em: <http://www.scielo.br/pdf/ sausoc/v19n4/09.pdf>. Acesso em: 20 fev. 2018.

PASCHOAL, T.; TAMAYO, A. Validação da escala de estresse no trabalho. Estudos de Psicologia, v. 9, n. 1, p. 45-52, 2004. Disponível em: <http://www.scielo.br/pdf/epsic/v9n1/22380.pdf> Acesso em: 5 out. 2017.

PEREIRA JORGE, I. M. Estresse no trabalho e desempenho dos Enfermeiros do hospital escola: um estudo de caso. 2010. 314f. Tese (Doutorado em Engenharia de Produção) - Universidade Federal de Santa Catarina, Florianópolis, 2010.

REZENDE, M. A. Influência do transporte sobre o nível de estresse dos trabalhadores: trajeto entre residência e local de trabalho. 2012. 124f. Dissertação (Mestrado em Engenharia de Produção) - Universidade Tecnológica Federal do Paraná, Ponta Grossa, 2012. Disponível em: <http://www.pg.utfpr.edu.br/dirppg/ppgep/ dissertacoes/arquivos/197/Dissertacao.pdf> Acesso em: 31 jan. 2018.

ROCHA, F. D. L. Burnout e Fadiga por Compaixão: o mal dos tempos modernos? 2016. 12f. Monografia (Programa de Aprimoramento Profissional) - Hospital Veterinário da Faculdade de Ciências Agrárias e Veterinárias, Universidade do Estado de São Paulo, Jaboticabal, 2016. Disponível em: <file:///C:/Users/ADM/ Downloads/PAP_Fabiana_Del_Lama_Rocha_484-2016.pdf $>$. Acesso em: 29 jan. 2018.

SADIR, M. A.; BIGNOTTO, M. M.; LIPP, M. E. N. Stress e qualidade de vida: influências de algumas variáveis pessoais. Paideia, v. 20, n. 45, p. 73-81, 2010. Disponível em: <http://www.scielo.br/pdf/paideia/ v20n45/a10v20n45.pdf>. Acesso em: 20 dez. 2017.

SANCHES, V. S. et al. Burnout e qualidade de vida em Residência Multiprofissional: um estudo longitudinal de dois anos. Revista Brasileira de Educação Médica, v. 40, n. 3, p. 430-436, 2016. Disponível em: <http://www.scielo.br/pdf/rbem/v40n3/1981-5271rbem-40-3-0430.pdf>. Acesso em: 29 jan. 2018. 
SILVA, M. R. A.; SILVEIRA, P. R. R. M. Estresse Ocupacional em enfermeiros residentes de um Programa de Residência

Multiprofissional em Saúde da Família. Revista Brasileira de Inovação Tecnologica em Saúde, v. 7, n. 1, p. 24-35, 2017 Disponível em: $<$ https://periodicos.ufrn.br/reb/article/view/11681/8939>. Acesso em: 20 dez. 2017.

SWAN, J. A.; MORAES, L. F. R.; COOPER, C. L.; Developing the occupational stress indicator (OSI) for use in Brazil: A report on the reliability and validity of the translated OSI. Stress Medicine, v. 9, n. 4, p. 247-253, 1993.

TRIBUNAL SUPERIOR DO TRABALHO - TST. Transtornos mentais relacionados ao trabalho são desafios a serem enfrentados na nova organização do trabalho. 2016. Disponível em: <http://www.tst.jus. br/web/trabalhoseguro/programa/-/asset_publisher/OSUp/content/ transtornos-mentais-relacionados-ao-trabalho-sao-desafios-a-seremenfrentados-na-nova-organizacao-do-trabalho>. Acesso em: 29 nov. 2017.

UNIVERSIDADE FEDERAL DO PARANÁ - UFPR. Departamento de Saúde Coletiva. Regimento Interno do Programa de Residência Multiprofissional em Saúde da Família. 2016. Disponível em: <http:// www.saude.ufpr.br/portal/saudecomunitaria/wp-content/uploads/ sites/30/2017/02/Regimento-Saude-da-Familia-23-09-2016.pdf>. Acesso em: 1 dez. 2017. 